\title{
Postischemic Synaptic Physiology in Area CA1 of the Gerbil Hippocampus Studied in vitro
}

\author{
L. Urban, ${ }^{1, a}$ K. H. Neill, ${ }^{2}$ B. J. Crain, ${ }^{2,3}$ J. V. Nadler, ${ }^{3,4}$ and G. G. Somjen ${ }^{1,3}$ \\ Departments of ${ }^{1}$ Cell Biology, ${ }^{2}$ Pathology, ${ }^{3}$ Neurobiology, and ${ }^{4}$ Pharmacology, Duke University Medical Center, Durham, \\ North Carolina 27710
}

\begin{abstract}
After transient forebrain ischemia in the Mongolian gerbil, CA 1b hippocampal pyramidal cells degenerate during a period of 2-4 d. We tested the hypothesis that this delayed neuronal death is preceded by excessive synaptic excitation. Hippocampal slices were prepared from gerbils that had been subjected to a 5 min occlusion of both common carotid arteries. Input/output curves demonstrated enhancement of the initial slope of the Schaffer collateral-commissural focally recorded EPSP at all stimulus currents between 5 and $10 \mathrm{hr}$ after the ischemic insult. The duration of the focally recorded EPSP also increased. At the same time, the excitability of the CA1b pyramidal cells decreased. Thus, the EPSP brought fewer pyramidal cells to threshold than the same size EPSP in control slices. During the first $14 \mathrm{hr}$ after ischemia, the antidromic population spike remained unaffected. By $24 \mathrm{hr}$ after ischemia, however, the focally recorded EPSP and both orthodromic and antidromic population spikes were markedly depressed, and they declined further over the next $2 \mathrm{~d}$. No recovery was detected. In the same slices, transient ischemia only mildly and reversibly affected the response of dentate granule cells to perforant path stimulation and did not affect their response to antidromic stimulation. Hippocampal slices adjacent to those used for electrophysiological recording were analyzed histologically. Examination of somatic argyrophilia confirmed that $\mathrm{CA} 1 \mathrm{~b}$ pyramidal cells suffered delayed neuronal death, whereas dentate granule cells remained intact. Pyramidal cell argyrophilia was, however, not detected until $2 \mathrm{~d}$ after these neurons had become virtually inexcitable.

We conclude that CA $1 \mathrm{~b}$ pyramidal cells begin to lose electrophysiological function well before definite morphological signs of degeneration become visible. The observation of enhanced excitatory transmission 5-10 hr after reperfusion is consistent with the idea that delayed ischemic neuronal death results, at least in part, from excessive excitation.
\end{abstract}

Neuronal cell death plays a major role in the functional deficits that follow episodes of cerebral ischemia (Brierley and Graham, 1984). Among the most vulnerable neurons to ischemia are the

\footnotetext{
Received Feb. 10, 1989; revised May 1, 1989; accepted June 5, 1989.

We wish to thank Dr. P. G. Aitken for his help with the statistical procedures. This research was supported by NIH grants NS 06233 and NS 18670 .

Correspondence should be addressed to J. V. Nadler, Department of Pharmacology, Box 3813, Duke University Medical Center, Durham, NC 27710.

a Permanent address: Department of Anatomy, University School of Medicine Debrecen, Debrecen 4012, Hungary.

Copyright $\odot 1989$ Society for Neuroscience $0270-6474 / 89 / 113966-10 \$ 02.00 / 0$
}

CAlb pyramidal cells of the hippocampus. The response of these neurons is unusual in that overt signs of degeneration are expressed gradually over a $2-4 \mathrm{~d}$ period. This "delayed neuronal death" was originally defined in animal models (Kirino, 1982; Pulsinelli et al., 1982; Kirino and Sano, 1984a; Kirino et al., 1984) but was subsequently described also in humans who were resuscitated after cardiac arrest (Petito et al., 1987). Experimental study of delayed neuronal death provides an opportunity to delineate the sequence of events between transient ischemia and neuronal degeneration, to investigate the factors that lead from one to the other, and possibly to devise therapeutic interventions.

The cellular and molecular mechanisms responsible for the selective vulnerability of particular CNS neurons to ischemia are poorly understood. It is generally believed that intolerance or resistance to ischemia reflects differences among neurons in their biochemical/biophysical properties and in their innervations. Studies of animal models have led to the development of an excitotoxic hypothesis for ischemic brain damage (Rothman and Olney, 1986; Choi, 1988). An excessively high extracellular concentration of excitatory amino acid can destroy any neuron that expresses the appropriate receptor (Olney, 1983). In the hippocampal formation, ischemia preferentially increases the extracellular concentrations of the excitatory transmitters, glutamate and aspartate (Benveniste et al., 1984; Hagberg et al., 1985). The exposure of CAlb pyramidal cells to a toxic concentration of excitatory amino acid may initiate the sequence of events that leads to the death of these neurons days later. By analogy, studies of cortical cell cultures demonstrated a $\mathrm{Ca}^{2+}$ dependent form of delayed neuronal death that can be initiated by either hypoxia (Goldberg et al., 1986) or a high concentration of excitatory amino acid (Choi, 1987). However, excitatory amino acids may play their most crucial role in ischemic neuronal death several hours after reperfusion.

Several observations support the idea that synaptic excitation during the first $24 \mathrm{hr}$ after reperfusion plays an etiological role in delayed neuronal death. CAl pyramidal cells receive their major innervation from ipsi- and contralateral CA3 pyramidal cells via the Schaffer collateral, commissural, and ipsilateral stratum oriens pathways (Gottlieb and Cowan, 1973; Swanson et al., 1978; Nadler et al., 1980). These excitatory amino acid pathways release both glutamate and aspartate (Nadler et al., 1976; Corradetti et al., 1983; Burke and Nadler, 1988). Both excitants, especially aspartate, can destroy hippocampal pyramidal cells (Nadler et al., 1981), probably through interaction with postsynaptic $N$-methyl-D-aspartate (NMDA) receptors. Delayed neuronal death appears to result from excessive $\mathrm{Ca}^{2+}$ influx 
(Choi, 1988), which could result, in turn, from the activation of NMDA receptors (Mayer et al., 1987; Murphy et al., 1987). Importantly, ischemic damage in area $\mathrm{CAlb}$ can be reduced by prior ablation of a hippocampal excitatory pathway (Wieloch et al., 1985; Onodera et al., 1986; Johansen et al., 1987; Jørgensen et al., 1987; Kaplan et al., 1989) or by the administration of an NMDA receptor antagonist (Boast et al., 1987, 1988; Gill et al., 1987). NMDA receptor antagonists are effective even when they are administered hours after reperfusion (Boast et al., 1988; Gill et al., 1988). A lesion of the Schaffer collateral pathway also retains some efficacy when it is made after reperfusion (Johansen et al., 1987). These results imply that ischemic degeneration involves the activation of NMDA receptors during the period after reperfusion and that preventing activation of these receptors can interrupt the degenerative process.

If CA $1 \mathrm{~b}$ hippocampal pyramidal cells die from excessive synaptic excitation during the period after reperfusion, this could come about either through the generation of postischemic seizures, the excessive firing of $\mathrm{CA} 3$ pyramidal cells in the absence of seizures, and/or through enhanced excitatory transmission in area CAlb. The involvement of seizure activity has been ruled out (Armstrong et al., 1989), and neuronal hyperactivity short of seizures appears insufficient by itself to destroy hippocampal neurons (Vicedomini and Nadler, 1987). Therefore, the present study utilized the gerbil carotid occlusion model of transient forebrain ischemia to test the hypothesis that CA1b pyramidal cell degeneration is preceded by a period of enhanced excitatory transmission. A preliminary account of this work has appeared (Urban et al., 1988).

\section{Materials and Methods}

Bilateral carotid occlusion. Adult male Mongolian gerbils (3-7 months of age, 60-100 gm; Tumblebrook Farms, West Brookfield, MA) were anesthetized with $2.5 \%$ halothane in room air. The common carotid arteries were isolated and occluded with Schwartz clips for $5 \mathrm{~min}$. Body temperature was maintained at $36-37^{\circ} \mathrm{C}$ during the occlusion (see Crain et al., 1988). The absence of blood flow during occlusion and the patency of the carotid arteries after the release of the clips were verified visually. In sham-operated animals, the carotid arteries were exposed but not occluded.

Animals were placed into either of 2 experimental groups. One group was used to identify changes in evoked responses within $14 \mathrm{hr}$ after the carotid occlusion; the other group to examine changes $1-10 \mathrm{~d}$ after the occlusion. In the short-survival group, 7 animals were killed immediately after the occlusion while still under halothane anesthesia. The other animals in this group were killed after recovery times of 1-2 $\mathrm{hr}(n=7)$ or $10 \mathrm{hr}(n=5)$. Members of the long-survival group were studied $1 \mathrm{~d}$ $(n=8), 2 \mathrm{~d}(n=8), 3 \mathrm{~d}(n=8)$ or $10 \mathrm{~d}(n=4)$ after carotid occlusion. Both electrophysiological and histological changes were examined in all animals. In addition, 7 sham-operated animals (survival times: $5-10$ $\min (n=2), 1 \mathrm{~d}(n=2), 2 \mathrm{~d}(n=2)$, and $3 \mathrm{~d}(n=1))$ and 15 unoperated control animals were studied. Twenty animals randomly distributed among the various treatment groups were selected for blind experiments. That is, the electrophysiological recordings and the data analysis were carried out without knowledge of when or whether the carotid arteries had been occluded.

Slice preparation and electrophysiological recording. At the appropriate survival times, the brain was removed under ether anesthesia (except for the 7 experimental and 2 sham-operated animals that were still ancsthetized with halothane). The hippocampi were removed and transverse slices $400 \mu \mathrm{m}$ thick were cut from the middle third and transferred to an interface chamber (Fine Science Tools, Vancouver, B.C., Canada). The slices were maintained in the chamber at $34.5^{\circ} \mathrm{C}$, oxygenated with warmed, humidified $95 \% \mathrm{O}_{2} / 5 \% \mathrm{CO}_{2}$, and superfused at $2 \mathrm{ml} / \mathrm{min}$ with artificial cerebrospinal fluid (ACSF), which contained (mmol/liter): $\mathrm{NaCl}, 130 ; \mathrm{KCl}, 3.5 ; \mathrm{NaH}_{2} \mathrm{PO}_{4}, 1.25 ; \mathrm{NaHCO}_{3}, 24 ; \mathrm{CaCl}_{2}$, $1.2 ; \mathrm{MgSO}_{4}, 1.2 ; \mathrm{D}$-glucose $10, \mathrm{pH} 7.4$, gassed continuously with $95 \%$
A

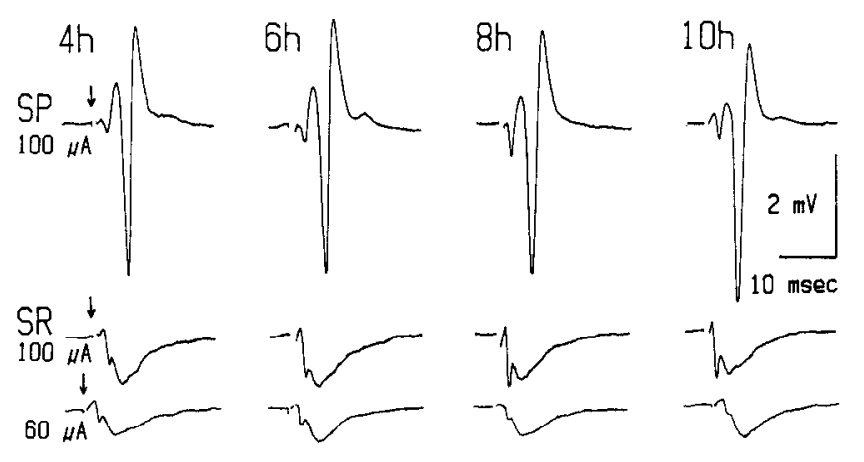

B

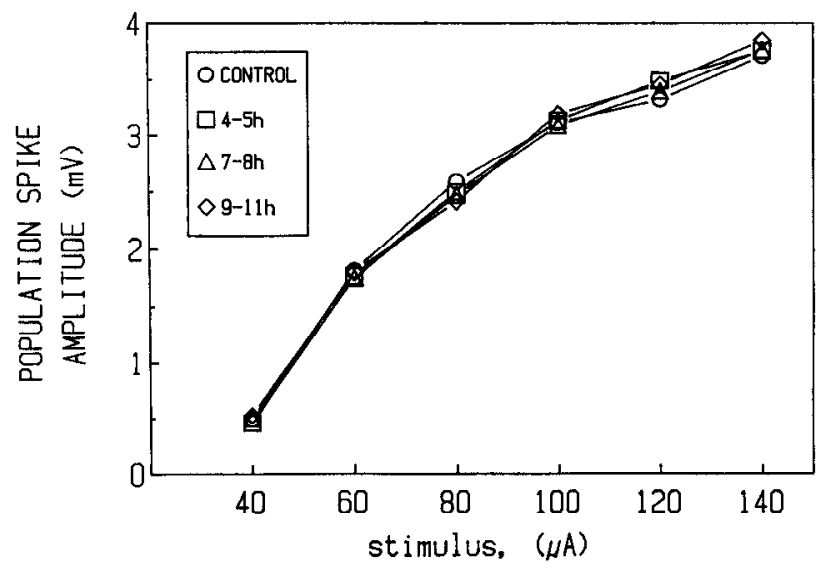

Figure 1. Orthodromic population spike and focally recorded EPSP (fEPSP) in area CA1b of control gerbil hippocampal slices. $A$, The fEPSPs were recorded in stratum radiatum $(S R)$ and population spikes in stratum pyramidale $(S P)$ after Schaffer collateral-commissural stimulation. Traces recorded from a single slice are shown at $4,6,8$, and $10 \mathrm{hr}$ after the slice was prepared. Each trace is an average of 10 individual sweeps. Responses were evoked by rectangular constant current pulses of 0.1 $\mathrm{msec}$ duration and the indicated intensity. In this and subsequent figures, arrows indicate the time of stimulation. $B$, Mean stimulus/response curves at different time intervals after slices were prepared $(N=8-9)$. This plot illustrates the constancy of orthodromic population spike amplitude during the recording period. The initial slope of the fEPSP remained similarly constant during this period.

$\mathrm{O}_{2} / 5 \% \mathrm{CO}_{2}$. Slices were allowed to recover in the chamber for $2.5 \mathrm{hr}$ before experimentation.

Constant current rectangular stimulus pulses $(0.1-0.2 \mathrm{msec}, 40-200$ $\mu \mathrm{A})$ were delivered through an insulated monopolar tungsten electrode (Frederick Haer \& Co., Waterville, ME). Extracellular potentials were recorded with glass micropipettes filled with $150 \mathrm{mM} \mathrm{NaCl}(2-6 \mathrm{M} \Omega)$. To determine input/output functions in area $\mathrm{CAlb}$, a stimulating electrode was positioned in stratum radiatum to activate the Schaffer collateral-commissural fibers, and recording electrodes were positioned both in the more medial portion of stratum radiatum and in the pyramidal cell body layer. For antidromic activation of pyramidal cells, the stimulating electrode was placed in the alveus. In the fascia dentata, focal potentials were recorded in the granule cell layer after stimulation of either the perforant path where it passes through the subiculum (orthodromic) or the mossy fibers (antidromic). Stimuli were delivered at the rate of $0.1 \mathrm{~Hz}$ to avoid interaction between individual evoked potentials. The responses to 4 pulses were averaged at each stimulus intensity (unless stated otherwise), digitized, and stored on computer disk. Electrophysiological recordings were made from 210 hippocampal slices prepared from 69 gerbils.

Data analysis. Analysis of digitized, averaged data was performed by a computer program, which automatically measured voltage differences or rates of change ("slopes") at manually selected points on each waveform (Aitken, 1985). The maximum rate of rise of the focally recorded 
Figure 2. Orthodromic population spikes $(S P)$ and fEPSPs $(S R)$ recorded simultaneously at various times after a 5 min carotid occlusion from 2 different slices prepared $2 \mathrm{hr}$ (recorded at 4,5 , $7 \mathrm{hr}$ ) or $10 \mathrm{hr}$ (recorded at $14 \mathrm{hr}$ ) after the occlusion. Traces represent responses of CA1 pyramidal cells to Schaffer collateral-commissural stimulation at the indicated stimulus strengths. Note the enhancement of both responses followed by depression, in contrast to synaptic responses in slices from control animals (Fig. 1).
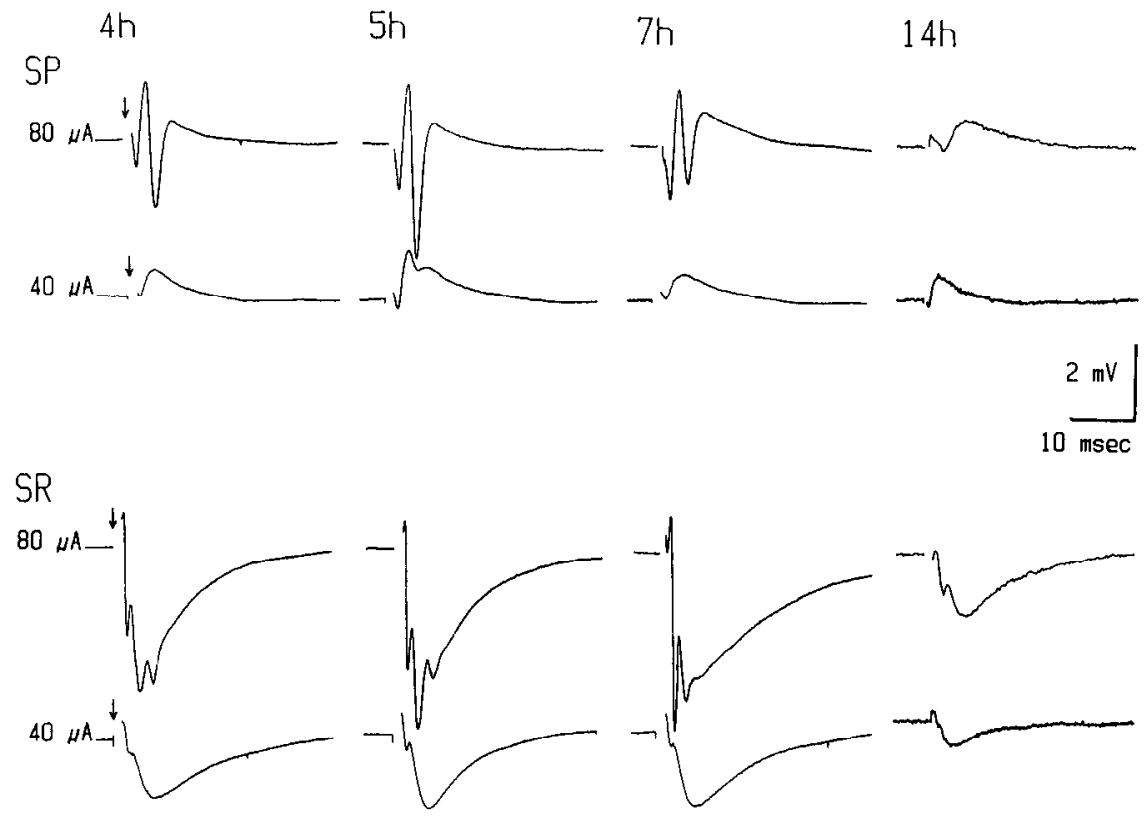

EPSP (fEPSP) was measured during the initial 0.5 msec segment of the negative wave recorded in stratum radiatum. The amplitude of the population spike recorded in stratum pyramidale was measured as the difference in voltage between the midpoint of a line drawn between onset and termination of the spike and its negative peak (Aitken, 1985; Balestrino et al., 1986). The initial slope of the fEPSP provides a measure of the synaptic drive imparted to the CAl pyramidal cells, whereas the amplitude of the population spike is related to the number of pyramidal cells brought to threshold by the stimulus (assuming that individual action potential amplitudes remain constant) (Andersen et al., 1971). Population spike amplitudes and fEPSP slopes were plotted as a function of stimulus intensity (stimulus-response curves). Population spike amplitude was also plotted as a function of fEPSP slope to estimate the responsiveness of the pyramidal cell population to synaptic input.

Grouped data were compared with a 2-way analysis of variance for both stimulus current and treatment, where treatment means the various time intervals between the end of the carotid occlusion and the recording. The standard error of percentage changes was calculated as proposed by McLean and Welch (1971). After the analysis of variance, means of the treatment groups were compared with those of unoperated controls with a Dunnett test.

Histology. All hippocampal slices rostral and caudal to those selected for electrophysiological recording were immediately placed in phosphate-buffered $4 \%(\mathrm{wt} / \mathrm{vol})$ paraformaldehyde, $\mathrm{pH} 7.4$. After at least 3 $\mathrm{d}$ fixation at $4^{\circ} \mathrm{C}$, the slices were frozen and cut into $40-\mu \mathrm{m}$-thick sections with a rotary freezing microtome. The sections were stained by a silver impregnation method which visualizes degenerating neuronal somata (Nadler and Evenson, 1989). Observers blinded to the experimental conditions and to the results of the electrophysiological experiments assessed the extent of neuronal degeneration in each case.

\section{Results}

\section{Evoked potentials during the first $14 \mathrm{hr}$ after carotid occlusion}

Because hippocampal slices from unoperated and sham-operated gerbils yielded indistinguishable results (e.g., Figs. 10, 11), they were normally combined into a single control group. In slices from control animals the threshold stimulus for evoking an orthodromic population spike in area CAlb was about 40 $\mu \mathrm{A}(0.1$ msec pulse duration) and a current of $120-140 \mu \mathrm{A}$ evoked a maximal response. Therefore, all stimulus-response curves were constructed with stimulus pulses of $40-140 \mu \mathrm{A}$ delivered in $20 \mu \mathrm{A}$ steps. The minimum stimulus strength which evoked a IEPSP was determined to be $20 \mu \mathrm{A}(0.1 \mathrm{msec}$ pulse duration), and the stimulus-response curve reached a maximum at $120-140 \mu \mathrm{A}$. These curves showed only minor changes during recordings made as long as $14 \mathrm{hr}$ after the slice was cut. Figure $1 A$ shows recordings from a single slice. Figure $1 B$ shows an example of averaged stimulus-response curves from all control slices that were studied for at least $9 \mathrm{hr}$.

In slices cut from gerbils that had undergone transient forebrain ischemia, evoked responses were not statistically different from those evoked in control slices for 3-4 hr after the ischemic period. Thereafter, marked changes were seen. These changes occurred at the same time after reperfusion, whether the slices were cut immediately and then maintained in the chamber or the animal was killed 1-10 hr after the occlusion. Both the population spike amplitude and fEPSP slope increased above the control value at all stimulus strengths 5-6 hr after the ischemic insult (Figs. 2-4). As expected, this change was most consistently evident when a stimulus current in the middle of the range was used. An $80 \mu \mathrm{A}$ pulse, for example, evoked a fEPSP whose slope was on average $85 \%$ greater than control and a population spike whose amplitude was $68 \%$ greater than control (Fig. 4). The amplitude of the orthodromic population spike then rapidly declined. At 9-10 hr after the occlusion, the population spike was significantly smaller than control, and at 14 $\mathrm{hr}$, a single pulse delivered at any stimulus intensity failed to drive the pyramidal cells. At the latter time, an orthodromic population spike could be evoked only if the synaptic response was potentiated (Fig. 5). By contrast, the slope of the fEPSP remained significantly elevated between 5 and $10 \mathrm{hr}$ after the carotid occlusion. Most strikingly, the slope of the fEPSP could be twice or more as steep as control 7-10 hr after the occlusion, while the population spike was near its control amplitude or smaller. A greatly depressed fEPSP could still be recorded 14 $\mathrm{hr}$ after the occlusion, when the orthodromic population spike had invariably failed.

Not only did transient ischemia increase the initial slope of the fEPSP, but it also increased its duration (Fig. 6). Responses evoked by a $60 \mu \mathrm{A}$ stimulus were chosen for quantitative analysis because the records from stratum radiatum were uncontaminated by a reflected population spike. In slices from 15 control animals studied every hour, fEPSP duration remained 
constant for at least $7 \mathrm{hr}$. In slices prepared from 7 experimental animals immediately after ischemia, however, fEPSP duration already significantly exceeded the control value $3 \mathrm{hr}$ after preparation (control: $16.6 \pm 0.4 \mathrm{msec}$; experimental: $20.1 \pm 0.9$ $\operatorname{msec}[$ means $\pm \mathrm{SEM}$ ]; $p<0.005$, Student's $t$ test after 2-way analysis of variance [treatment $x$ time] with repeated measures [time] yielded $p<0.01$ for both variables and for the interaction between them). The duration of the fEPSP increased progressively with time after the carotid occlusion. Linear regression revealed that for the first $7 \mathrm{hr}$, fEPSP duration increased by an average of 1.1-1.2 $\mathrm{msec} / \mathrm{hr}$. At the end of this period, the fEPSP lasted for $24.4 \pm 0.6 \mathrm{msec}$, compared with a corresponding control value of $16.7 \pm 0.6 \mathrm{msec}$ (means $\pm \mathrm{SEM} ; p<0.001$, Student's $t$ test). Unfortunately, the analysis could not be continued past $7 \mathrm{hr}$, bccausc most of the slices from experimental gerbils did not remain viable much beyond this time.

The difference in the rates with which the orthodromic population spike and fEPSP deteriorate is emphasized in Figure 7. A given fEPSP elicited a population spike smaller than control at all tested survival times. This finding demonstrates a progressive loss in pyramidal cell excitability coincident with the lengthening of the IEPSP, but which began before the initial slope of the fEPSP was enhanced. Thus, transient forebrain ischemia in the gerbil alters the response to stimulation of Schaffer collateral-commissural fibers in 2 ways: by facilitating synaptic transmission and by depressing pyramidal cell excitability.

Although all responses to orthodromic stimulation were markedly depressed $11 \mathrm{hr}$ after transient ischemia, population spikes evoked by antidromic stimuli from 40 to $140 \mu \mathrm{A}$ remained unchanged for $14 \mathrm{hr}$ (Figs. 3, 5). Responses evoked in the fascia dentata by either orthodromic (Fig. $5 \mathrm{C}$ ) or antidromic stimulation appeared normal throughout this period, although this question was not systematically studied.

\section{Electrophysiological and morphological signs of progressive neuronal degeneration}

The earliest histopathologic evidence of ischemic damage appeared in slices prepared $24 \mathrm{hr}$ after the carotid occlusion (Fig. 8 ). At this time CAl pyramidal cells stained more lightly than normal in sections impregnated with silver. The pallor of the cytoplasm contrasted with the prominent darkly stained nucleolus. Somatic argyrophilia was confined to the dentate hilus at this time. Two days after the occlusion, many pyramidal cells in area CAla had become argyrophilic, but the CA $1 \mathrm{~b}$ pyramidal cells continued to exhibit pallor. Finally, on the third postischemic day the CA1b pyramidal cells also became argyrophilic. The dentate granule cells appeared not to have been damaged. The extent and time course of somatodendritic degeneration observed in the present material were virtually identical to results obtained from hippocampi fixed by perfusion in situ (Crain et al., 1988).

Electrophysiological responses to both orthodromic and antidromic stimulation in area CA1b were markedly depressed 1 $\mathrm{d}$ after the carotid occlusion and wcre virtually absent when tested 3 or $10 \mathrm{~d}$ after the occlusion. Examples selected from single experiments are shown in Figure 9 and statistical comparisons of all data in Figure 10.

As in the previous series of short-survival experiments, the orthodromic population spike decreased in amplitude and disappeared more rapidly than the fEPSP. By contrast, the compound action potential of the afferent fibers or presynaptic volley was always recorded (Fig. 9), consistent with the relative resis-
A

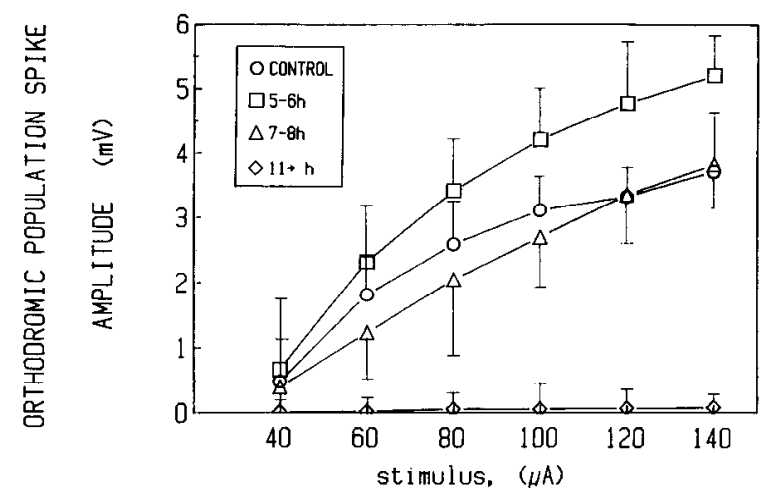

B
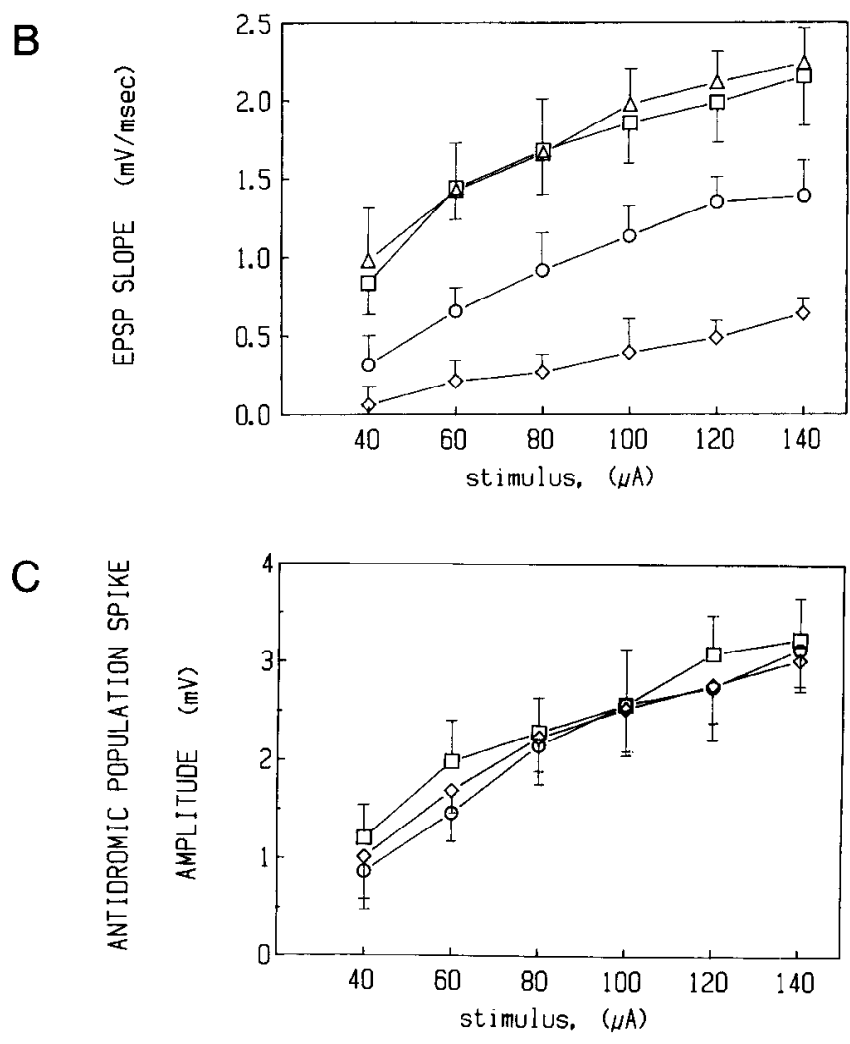

Figure 3. Effects of transient forebrain ischemia on the orthodromic and antidromic activation of CAlb pyramidal cells. Mean values of orthodromic population spike amplitude $(A)$, slope of the fEPSP $(B)$, and antidromic population spike amplitude $(C)$ are plotted as functions of stimulus strength at various times after a 5 min carotid occlusion. Control values were averaged for all recording times because these responses were essentially constant (Fig. 1). Experimental values include data from all slices, whether prepared immediately after the occlusion or 1-2 or $10 \mathrm{hr}$ later. Note the transient enhancement of responses to orthodromic stimulation and the subsequent depression of orthodromically evoked responses before there was any change in amplitude of the antidromic population spike. Control, $n=22 ; 5-6 \mathrm{hr}, n=11 ; 7-8$ $\mathrm{hr}, n=8 ; 11-14 \mathrm{hr}, n=10$.

tance of the Schaffer collateral-commissural fibers to ischemia (Johansen et al., 1984).

It can be seen in Figures 9 and 10 that the orthodromic population spike was less profoundly depressed in slices from $1 \mathrm{~d}$ survivors than it appeared to be at 11-14 hr after the carotid occlusion in the first set of experiments (Figs. 2-4). There may perhaps be a temporary, paradoxical recovery of the synaptic response in the waning hours of the first day. It seems more 
Figure 4. Statistical analysis of changes in the response of CA $1 \mathrm{~b}$ pyramidal cells to orthodromic stimulation after transient forebrain ischemia. Data obtained with 2 representative submaximal stimulus currents are shown. Each bar represents an averaged value of population spike amplitude or fEPSP slope expressed as a percentage $( \pm$ SEM $)$ of the control response recorded at an equivalent time. The experimental slices were prepared immediately after the carotid occlusion. The analysis includes results from the 7 control and 7 experimental slices. Two-way analysis of variance showed significant differences between experimental and control population spike amplitudes and fEPSP slopes evoked at both stimulus intensities $(p<0.01$ for both treatment and stimulus current). ${ }^{*} p<0.05 ;{ }^{* *} p<0.01$ (Dunnett test, $d f: 29$ ).

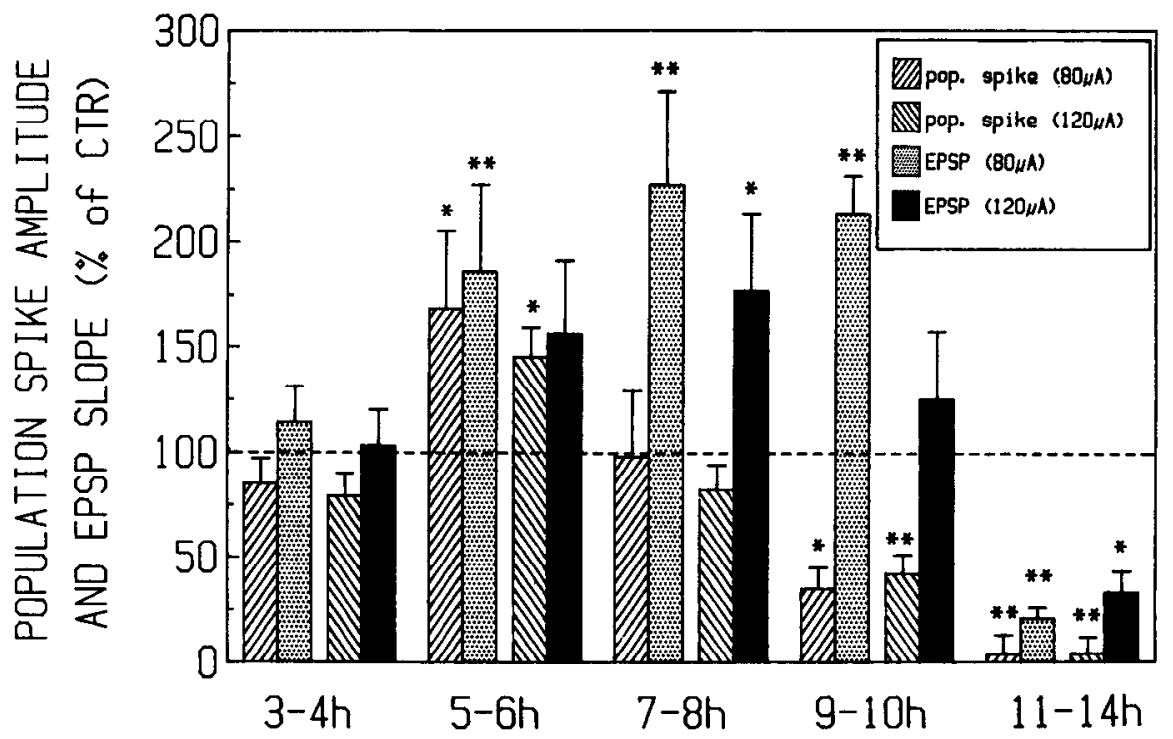

likely, however, that this discrepancy is due to the different conditions employed in the 2 sets of experiments. In the first series of experiments, the slices were prepared soon after the ischemic insult and then maintained in a superfusion chamber. In the second series of experiments, the hippocampus remained in situ for $24 \mathrm{hr}$ after the carotid occlusion and the recordings were made $2.5 \mathrm{hr}$ thereafter. Possibly the degenerative process proceeds somewhat more rapidly in a superfused hippocampal slice than in the intact animal.

Transient ischemia also tended to depress the population spike evoked on the first, second, and third postischemic days by perforant path stimulation in the fascia dentata (Fig. 11). There was, however, much greater variability in the postischemic orthodromic recordings from the fascia dentata than in those from area CAlb; thus, the apparent depression of the perforant path population spike was not statistically significant. Full recovery was obtained by the 10th postischemic day. Measurements of the antidromic population spike in the fascia dentata were much more consistent, and no significant changes were observed.
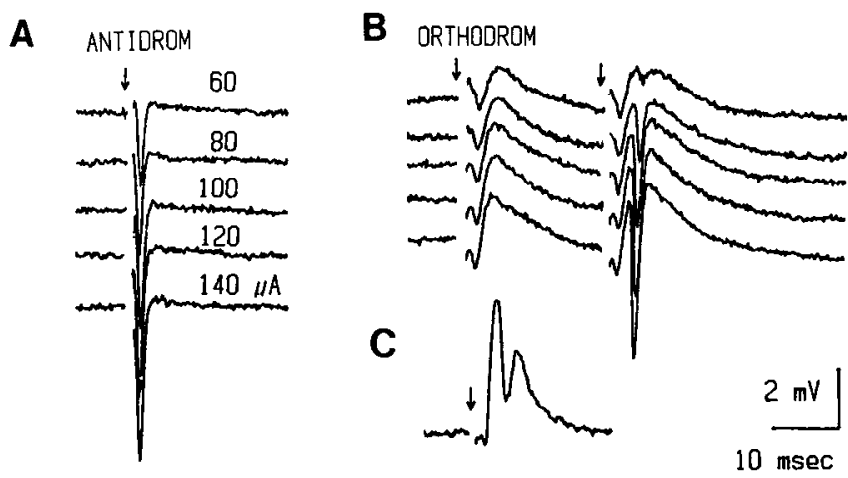

Figure 5. Selective reduction of the Schaffer collateral-commissural population spike $14 \mathrm{hr}$ after transient ischemia. Antidromic population spikes were present at this time $(A)$, whereas a single orthodromic stimulus failed to evoke a population spike $(B)$. However, an orthodromic population spike could still be evoked by the second of a pair of stimuli separated by $20 \mathrm{msec}$. In contrast to area CA1b, an orthodromic population spike could be evoked in the fascia dentata with a single stimulus to the perforant path $(C)$.

\section{Discussion}

In addressing the mechanism of delayed neuronal death, the use of hippocampal slices permits a distinction between electrophysiological changes attributable to the effects of ischemia on the degenerating neurons themselves and changes in relatively normal neurons produced secondarily by an abnormal postischemic environment in situ. This approach eliminates such possible complicating factors as damage to cerebral blood vessels and reduces the influence of others, such as acidosis and hyperkalemia, especially when slices are prepared soon after reperfusion. An important finding of this study was that the short-
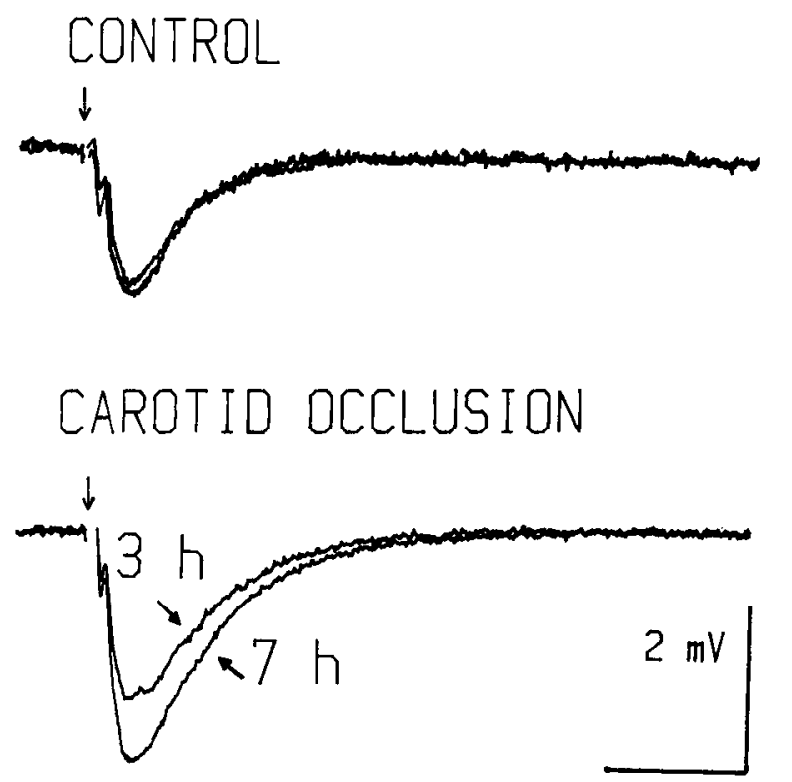

$10 \mathrm{msec}$

Figure 6. Bilateral carotid occlusion increases the duration of the fEPSP evoked by stimulation of the Schaffer collateral-commissural fibers in area CAlb (stimulus strength, $60 \mu \mathrm{A}$ ). Traces were recorded 3 and $7 \mathrm{hr}$ after the slice was prepared. The experimental slice was prepared immediately after the occlusion. 


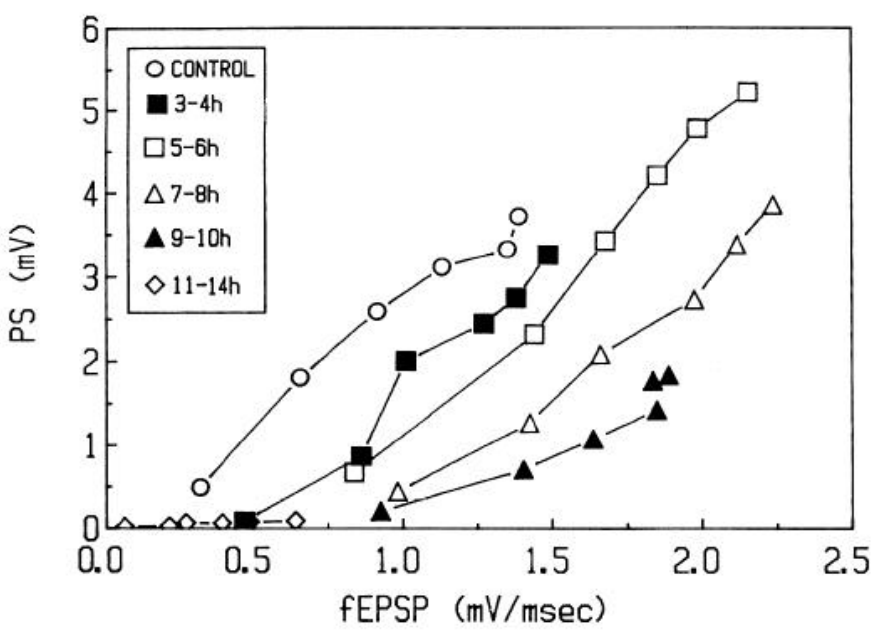

Figure 7. Orthodromic population spike $(P S)$ amplitude, as a function of Schaffer collateral-commissural fEPSP slope after transient forebrain ischemia. The shift of the curve to the right suggests a progressive depression of pyramidal cell excitability which begins even before the fEPSP is enhanced. See Figure 3 for other details.

term effects of transient ischemia proceeded at about the same rate in vitro as they did in situ. Thus, electrophysiological changes which took place during the first $14 \mathrm{hr}$ were detected at the same time after the carotid occlusion, regardless of when the slice was cut. This observation encourages the view that postischemic events identified in vitro also occur in situ.

With use of hippocampal slices, transient ischemia was found to produce 2 changes in the excitatory synaptic physiology of area CA1b: an enhancement of the Schaffer collateral-commissural fEPSP that was most dramatic between 5 and $10 \mathrm{hr}$ after reperfusion and depression of pyramidal cell excitability throughout the period of observation.

\section{Enhanced fEPSP}

Transient enhancement of the Schaffer collateral-commissural fEPSP several hours after reperfusion was the most interesting finding of this study. Both the initial slope and the duration of the fEPSP increased. This result is consistent with the idea that a brief period of ischemia leads to facilitation of excitatory synaptic transmission and thus to excitotoxic cell death. Transient ischemia did not, however, alter the response of dentate granule cells to stimulation of the perforant path at this time. Thus, the delayed enhancement of excitatory synaptic transmission may be specific to regions of ischemic damage.

Even though the amplitude of the orthodromic population spike initially increased along with the fEPSP, pyramidal cell excitability was already impaired $4 \mathrm{hr}$ after the ischemic insult, and it declined progressively with time. That is, the larger fEPSP brought a smaller number of pyramidal cells to threshold than did the same size fEPSP in control slices. The changes in both the fEPSP and orthodromic population spike could be largely explained by hyperpolarization of the postsynaptic cell, as by the activation of a resting $\mathrm{K}^{+}$conductance. Cerebral ischemia induces states of hypoxia and hypoglycemia within the brain, and each of these states activates a $\mathrm{K}^{+}$conductance in hippocampal pyramidal cells (Hansen et al., 1982; Fujiwara et al., 1987; Krnjević and Leblond, 1987; Spuler et al., 1988). However, enhancement of $\mathrm{K}^{+}$conductance is reversible after reoxygenation or restitution of normal glucose. Another possibility is that the enhancement of Schaffer collateral-commissural synaptic transmission and the loss of pyramidal cell excitability were at least partially independent events. In principle, synaptic transmission could have been enhanced through either increased transmitter release or an augmented postsynaptic response to the transmitter. These possibilities cannot be distinguished by the present experimental approach. However, our knowledge of transmission at Schaffer collateral-commissural synapses suggests several mechanisms by which either transmitter release or the postsynaptic response to the transmitter could be enhanced.

During low-frequency stimulation of the Schaffer collateralcommissural fibers, as employed in the present study, synaptic transmission normally involves activation of only the postsynaptic quisqualate receptor (Collingridge et al., 1983; Ganong et al., 1986). Quisqualate receptor activation presumably depends on the release of glutamate only, because aspartate appears to interact very weakly with this receptor (Honoré et al., 1982; Mayer and Westbrook, 1987). However, NMDA receptors also
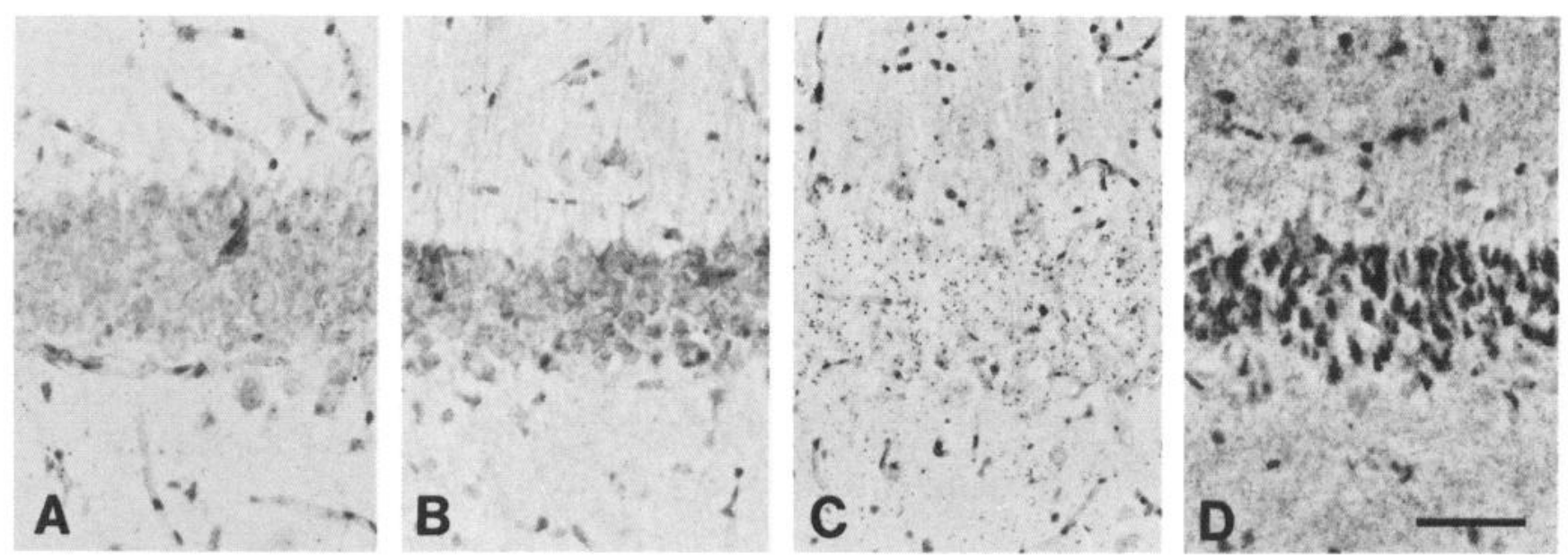

Figure 8. Hippocampal area CA1b from a control slice $(A)$ and from a slice cut $10(B), 24(C)$ or $72(D)$ hr after a bilateral carotid occlusion. Silver impregnation. Pyramidal cell bodies are normally stained in $A$ and $B$. In $C$, their cytoplasm stains so poorly that only their prominent argyrophilic nucleoi can be clearly seen. In $D$, the neurons exhibit the argyrophilia characteristic of degenerating somata. Scale bar, $100 \mu \mathrm{m}$. 
Figure 9. Effect of a 5 min carotid occlusion on orthodromically evoked responses recorded in stratum radiatum $(S R)$ and stratum pyramidale $(S P)$ of hippocampal area CAlb and in the granule cell layer of the fascia dentata $(F D)$. Each column of traces was recorded from an individual slice studied at the indicated survival time. $\mathrm{CON}$ $T R O L$ recordings represent responses in a hippocampal slice prepared from an unoperated animal. The selective loss of synaptic transmission in area CAlb is demonstrated by the relative constancy of the synaptic responses recorded in the fascia dentata $(F D)$ of the same slices. Note the persistence of a "presynaptic volley" in stratum radiatum of area CA1 throughout this period.

exist at this site and their activation contributes to the EPSP under certain circumstances: during high-frequency stimulation (Herron et al., 1986; Collingridge et al., 1988b), when the postsynaptic cell is tonically depolarized (Collingridge et al., 1988a), when synaptic inhibition is reduced (Wigström et al., 1985; Dingledine et al., 1986; Collingridge et al., 1988a), or when the extracellular concentration of $\mathrm{Mg}^{2+}$ is reduced (Herron et al., 1985; Coan and Collingridge, 1987; Collingridge et al., 1988a). Both glutamate and aspartate serve as agonists at the NMDA receptor (Olverman et al., 1984; Mayer and Westbrook, 1987). Thus, the precise effect of enhanced excitatory transmitter release would depend on whether the release of glutamate, aspartate, or both was enhanced, as well as on whether conditions existed that favored the activation of normally dormant NMDA receptors.

One piece of evidence consistent with elevated transmitter release is the rapid down-regulation of adenosine Al receptors observed after brief forebrain ischemia in the gerbil (Lee et al., 1986). Endogenous adenosine depresses the release of both glutamate and aspartate at Schaffer collateral-commissural synapses by activating the Al receptor (Burke and Nadler, 1988). Furthermore, adenosine receptor agonists can protect vulnerable neurons from ischemic, hypoxic, or hypoglycemic damage (Evans et al., 1987; Goldberg et al., 1988). Thus, transient ischemia might enhance the release of these transmitters by reducing the ability of adenosine to regulate the release process.

The postsynaptic response to transmitter could have been enhanced in several ways. One attractive possibility is the involvement of NMDA receptors in the EPSP. When the $\mathrm{Mg}^{2+}$ block of the NMDA receptor channel is overcome through repetitive stimulation, depressed synaptic inhibition, or reduction of the extracellular $\mathrm{Mg}^{2+}$ concentration, activation of this receptor adds a slowly developing and long-lasting component to the EPSP (Collingridge et al., 1988a). Thus, a progressive enhancement of NMDA receptor function could account for the increased duration of the fEPSP. Such an effect might also have increased the initial slope of the fEPSP, although the degree to which activation of the NMDA receptor can influence fEPSP slope remains to be determined. Transient ischemia might unmask NMDA receptors by increasing receptor density, depressing synaptic inhibition, tonically depolarizing the pyramidal cell or changing the structure or conformation of the receptor. Recently, Andiné et al. (1988) reported enhanced stimulation-induced $\mathrm{Ca}^{2+}$ uptake in the dendritic layer of area CAl $6 \mathrm{hr}$ after transient ischemia in the rat. This $\mathrm{Ca}^{2+}$ uptake was reduced by administration of the NMDA receptor antagonist ketamine, supporting the involvement of synaptically activated NMDA receptors in neuropathological events during the postischemic period. The ability of NMDA receptor antagonists to attenuate the ischemia-induced degeneration of CA 1 pyramidal cells when they are administered hours after ischemia (Boast et al., 1988; Gill et al., 1988) encourages the view that unmasking of NMDA receptors does in fact take place.

\section{Loss of pyramidal cell excitability}

The progressive loss of pyramidal cell excitability must be at least partly related to the degeneration of CA $1 \mathrm{~b}$ pyramidal cells, although the involvement of other possible factors, such as enhanced synaptic inhibition, cannot be excluded. Because the duration of the fEPSP increased and pyramidal cell excitability declined over similar time courses, these 2 effects of ischemia may have similar underlying mechanisms. For example, if the larger fEPSP resulted from the progressive unmasking of NMDA receptors, the same mechanism could lead to pyramidal cell dysfunction. Studies of this question are in progress.

The orthodromic population spike was affected at a much earlier stage than the antidromic population spike. This difference does not necessarily imply the existence of separate mechanisms, however, because the relative insensitivity of the antidromic spike may simply reflect the higher safety factor for the generation of antidromic, as opposed to orthodromic, action potentials. Because depressed excitability in response to orthodromic stimulation occurs at a time when the degenerative process can be halted by appropriate interventions (Johansen 
A

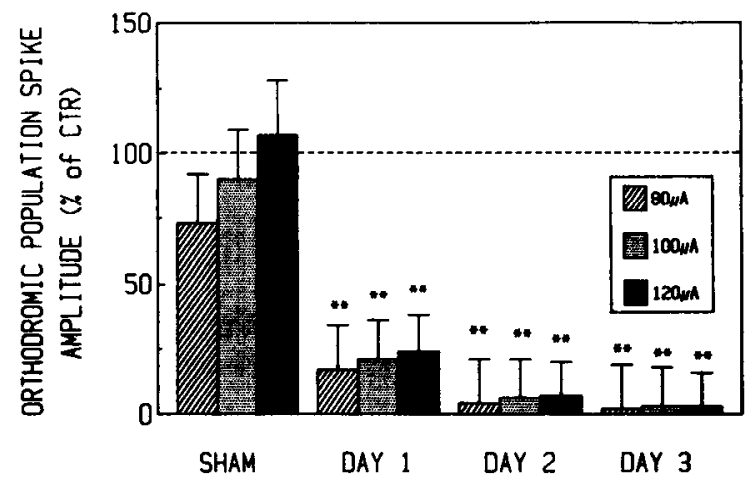

B

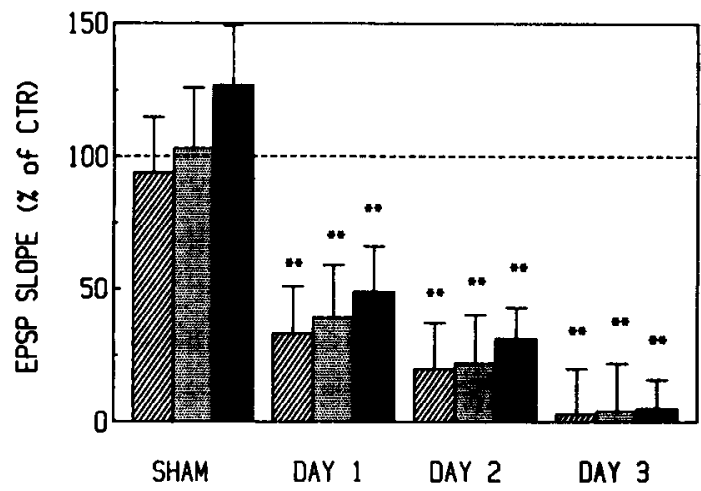

C

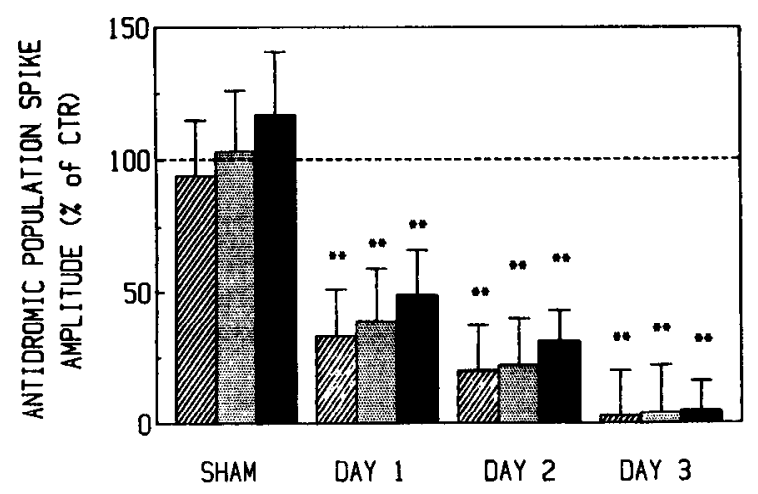

Figure 10. Quantitative analysis of evoked responses in area CA1b 1$3 \mathrm{~d}$ after a $5 \mathrm{~min}$ carotid occlusion. Each bar represents an averaged value of population spike amplitude $(A, C)$ or slope of the fEPSP $(B)$ expressed as in Figure 4. Slices from 15 unoperated gerbils were used as controls for these measurements. All slices from sham-operated animals yielded similar results, regardless of the survival time. Therefore, data from all these slices were combined. Note the marked decline of all evoked responses $1 \mathrm{~d}$ after transient ischemia and the loss of virtually any response on day 3 . $\left(N_{\mathrm{SHAM}}=7 ; N_{\mathrm{DAY} 1}=8 ; N_{\mathrm{DAY} 2}=8 ; N_{\mathrm{DAY} 3}=8\right)$ ${ }^{* *} p<0.01$ [Dunnett test: $d f(A), 119 ; d f(B), 87 ; d f(C), 71$; after 2-way analysis of variance yielded $p<0.01$ for both treatment and stimulus current].

et al., 1987; Boast et al., 1988; Gill et al., 1988), this effect of ischemia characterizes an early, reversible stagc of degencration. No histopathological changes were observed in area CAlb at this time. Indeed, depressed excitability might be viewed simply as a "compensatory" response to enhanced synaptic function. The orthodromically evoked, but not the antidromically evoked, firing of CAlb pyramidal cells is also depressed during superfusion of hippocampal slices with a medium deficient in glucose (Fan et al., 1988).

In contrast, the depression of antidromically evoked firing,

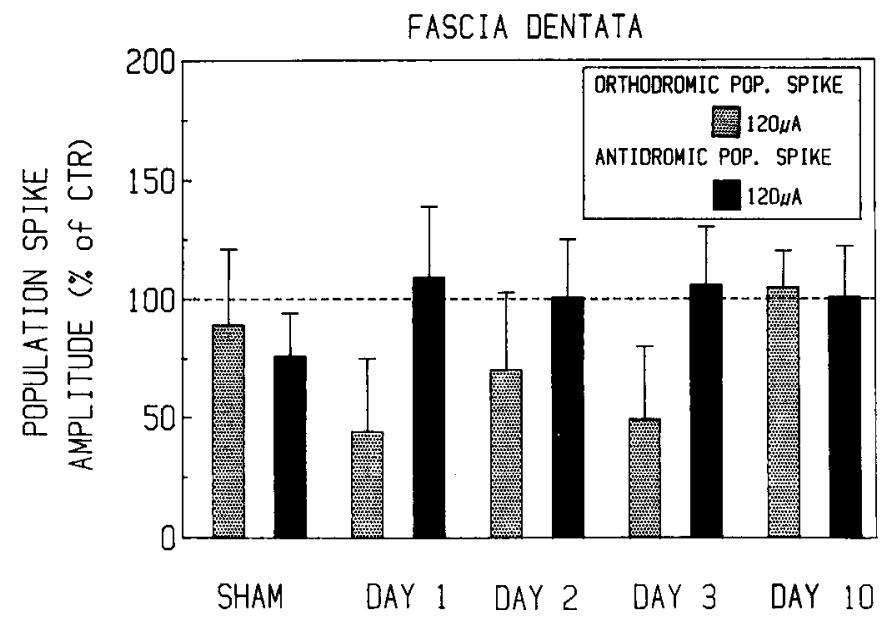

Figure 11. Quantitative analysis of orthodromic and antidromic population spikes recorded in the fascia dentata at various times after transient forebrain ischemia (for details see Figures 4 and 10). None of the apparent changes was statistically significant $(p>0.05$ for both treatment and stimulus current by 2-way analysis of variance). The number of slices used in these experiments was the same as indicated in Figure 10 , except that $N_{\text {DAY10 }}$ was 4 .

first detected $24 \mathrm{hr}$ after ischemia, appears to be associated with pathological changes in the CAlb pyramidal cell that may be irreversible. When the antidromic population spike declines, the nucleoli of these cells exhibit intense argyrophilia and stand out prominently against the very pale cytoplasm. This pallor may be the light microscopic expression of the disaggregation of polyribosomes and dilation of the cisternae of the endoplasmic reticulum demonstrated by electron microscopy (Kirino and Sano, 1984b; Petito and Pulsinelli, 1984). At $72 \mathrm{hr}$ after ischemia, there was a striking correlation between the almost complete loss of response to stimulation and the development of somatic argyrophilia by virtually all the CAlb pyramidal cclls. Thesc changes in pyramidal ccll excitability may be contrasted with the modest effects of transient ischemia observed in the fascia dentata. In the latter region, the orthodromic population spike was slightly, but only transiently, depressed 1-3 $\mathrm{d}$ after ischemia and the antidromic population spike was little affected. In accordance with the recovery of a normal synaptic response and retention of antidromically evoked firing, there was no morphological evidence of granule cell degeneration.

Although we found a strong quantitative correlation between pyramidal cell degeneration and the loss of electrophysiological responsiveness by these cells, pyramidal cell excitability markedly declined before clear morphological signs of degeneration appeared. Neither orthodromic nor antidromic stimulation evoked a sizable population spike $24 \mathrm{hr}$ after ischemia. Yet previous histological (Kirino, 1982; Kirino and Sano, 1984a; Crain et al., 1988) and electron microscopic (Kirino and Sano, 1984b) studies suggested that the CAlb pyramidal cells do not degenerate for another $2 \mathrm{~d}$. We confirmed in the present study that these cells do not become argyrophilic until about $72 \mathrm{hr}$ after ischemia. Thus, ischemia-induced degeneration of CA1b pyramidal cells may proceed more rapidly than morphological studies would suggest.

The peculiar appearance of CA1b pyramidal cells $24-48 \mathrm{hr}$ after transient ischemia merits additional comment. Our electrophysiological data suggest that an intensely argyrophilic nu- 
cleolus and pale cytoplasm denote a neuron that, while still intact, has lost its functional competence. Recent studies demonstrated that CA1b pyramidal cells which were protected from ischemia-induced degeneration by prior ablation of an excitatory hippocampal pathway (Kaplan et al., 1989) or by administration of an NMDA receptor antagonist (Warner et al., 1990) also exhibit this abnormal appearance and retain it for several weeks at least. These findings are relevant to the proposed clinical use of NMDA receptor antagonists to prevent ischemic brain damage (Meldrum, 1985; Rothman and Olney, 1986; Choi, 1988). It seems possible that neurons saved from ischemia-induced degeneration by interrupting the excitotoxic process are so damaged that, although viable, they are unable to carry out their normal physiological functions. If so, then conventional morphological assessments of ischemic damage overestimate the efficacy of anti-ischemic drugs. One might more realistically assess the benefits of treatment through electrophysiological monitoring and/or careful analysis of silver-impregnated brain sections.

\section{References}

Aitken, P. G. (1985) Kainic acid and penicillin: Differential effects on cxcitatory and inhibitory interaction in the CAl region of the hippocampal slice. Brain Res. 325: 261-269.

Andersen, P., T. V. P. Bliss, and K. K. Skrede (1971) Unit analysis of hippocampal population spikes. Exp. Brain Res. 13: 208-221.

Andiné, P., I. Jacobson, and H. Hagberg (1988) Calcium uptake evoked by electrical stimulation is enhanced postischemically and precedes delayed neuronal death in CAl of rat hippocampus: Involvement of $N$-methyl-D-aspartate receptors. J. Cerebr. Blood Flow Metab. 8: 799807.

Armstrong, D. R., K. H. Neill, B. J. Crain, and J. V. Nadler (1989) Absence of electrographic seizures after transient forebrain ischemia in the Mongolian gerbil, Brain Res. 476: 174-178.

Balestrino, M., P. G. Aitken, and G. G. Somjen (1986) The effects of moderate changes of extracellular $\mathrm{K}^{+}$and $\mathrm{Ca}^{2+}$ on synaptic and neural function in the CAl region of the hippocampal slice. Brain Res. 377: 229-239.

Benveniste, H., J. Drejer, A. Schousböe, and N.-H. Diemer (1984) Elevation of the extracellular concentrations of glutamate and aspartate in rat hippocampus during transient cerebral ischemia monitored by intracerebral microdialysis. J. Neurochem. 43: 1369-1374.

Boast, C. A., S. C. Gerhardt, and P. Janak (1987) Systemic AP7 reduces ischemic brain damage in gerbils. In Excitatory Amino Acid Transmission, T. P. Hicks, D. Lodge, and H. McLennan, eds., pp. 249252, Liss, New York.

Boast, C. A., S. C. Gerhardt, G. Pastor, J. Lehmann, P. E. Etienne, and J. M. Liebman (1988) The $N$-methyl-D-aspartate antagonists CGS 19755 and CPP reduce ischemic brain damage in gerbils. Brain Res. 442: 345-348.

Bricrlcy, J. B., and D. I. Graham (1984) Hypoxia and vascular disorders of the central nervous system. In Greenfield's Neuropathology, 4 th ed., J. H. Adams, J. A. N. Corsellis, and L. W. Duchen, eds., pp. 125-207, Edward Arnold, London.

Burke, S. P., and J. V. Nadler (1988) Regulation of glutamate and aspartate release from slices of the hippocampal CA1 area: Effects of adenosine and baclofen. J. Neurochem. 51: 1541-1551.

Choi, D. W. (1987) Ionic dependence of glutamate neurotoxicity in cortical cell culture. J. Neurosci. 7: 369-379.

Choi, D. W. (1988) Glutamate neurotoxicity and diseases of the nervous system. Neuron $1: 623-634$.

Coan, E. J., and G. L. Collingridge (1987) Characterization of N-methyl-D-aspartate receptor component of synaptic transmission in rat hippocampal slices. Neuroscience 22: 1-8.

Collingridge, G. L., S. J. Kehl, and H. McLennan (1983) Excitatory amino acids in synaptic transmission in the Schaffer collateral-commissural pathway of the rat hippocampus. J. Physiol. (Lond.) 334: 33-46.

Collingridge, G. L., C. E. Herron, and R. A. J. Lester (1988a) Synaptic activation of N-methyl-D-aspartate receptors in the Schaffer collateralcommissural pathway of rat hippocampus. J. Physiol. (Lond.) 399: 283-300.

Collingridge, G. L., C. E. Herron, and R. A. J. Lester (1988b) Frequency-dependent $\mathrm{N}$-methyl-D-aspartate receptor-mediated synaptic transmission in rat hippocampus. J. Physiol. (Lond.) 399: 301-312.

Corradetti, R., G. Moneti, F. Moroni, G. Pepeu, and A. Wieraszko (1983) Electrical stimulation of the stratum radiatum increases the release and neosynthesis of aspartate, glutamate and $\gamma$-aminobutyric acid in rat hippocampal slices. J. Neurochem. 41: 1518-1525.

Crain, B. J., W. D. Westerkam, A. H. Harrison, and J. V. Nadler (1988) Selective neuronal death after transient forebrain ischemia in the Mongolian gerbil: A silver impregnation study. Neuroscience 27:387402.

Dingledine, R., M. A. Hynes, and G. L. King (1986) Involvement of $N$-methyl-D-aspartate receptors in epileptiform burst firing in the rat hippocampal slice. J. Physiol. (Lond.) 380: 175-189.

Evans, M. C., J. H. Swan, and B. S. Meldrum (1987) An adenosine analogue, 2-chloroadenosine, protects against long term development of ischemic cell loss in the rat hippocampus. Neurosci. Lett. 83: 287292.

Fan, P., P. A. O'Regan, and J. C. Szerb (1988) Effect of low glucose concentration on synaptic transmission in the rat hippocampal slice. Brain Res. Bull. 21: 741-747.

Fujiwara, N., H. Higashi, K. Shimoji, and M. Yoshimura (1987) Effects of hypoxia on rat hippocampal neurons in vitro. J. Physiol. (Lond.) 384: 131-151.

Ganong, A. H., A. W. Jones, J. C. Watkins, and C. W. Cotman (1986) Parallel antagonism of synaptic transmission and kainate/quisqualate responses in the hippocampus by piperazine-2,3-dicarboxylic acid analogs. J. Neurosci. 6: 930-937.

Gill, R., A. C. Foster, and G. N. Woodruff (1987) Systemic administration of MK-801 protects against ischemia-induced hippocampal neurodegeneration in the gerbil. J. Neurosci. 7: 3343-3349.

Gill, R., A. C. Foster, and G. N. Woodruff (1988) MK-801 is neuroprotective in gerbils when administered during the postischemic period. Neuroscience 25: 847-855.

Goldberg, W. J., R. M. Kadingo, and J. N. Barrett (1986) Effect of ischemia-like conditions on cultured neurons: Protection by low $\mathrm{Na}^{+}$, low $\mathrm{Ca}^{2+}$ solutions. J. Neurosci. 6: 3144-3151.

Goldberg, M. P., H. Monyer, J. H. Weiss, and D. W. Choi (1988) Adenosine reduces cortical neuronal injury induced by oxygen or glucosc deprivation in vitro. Neurosci. Lett. 89: 323-327.

Gottlieb, D. I., and W. M. Cowan (1973) Autoradiographic studies of the commissural and ipsilateral association connections of the hippocampus and dentate gyrus of the rat. I. The commissural connections. J. Comp. Neurol. 149: 393-422.

Hagberg, H., A. Lehmann, M. Sandberg, B. Nystrom, I. Jacobson, and A. Hamberger (1985) Ischemia-induced shift of inhibitory and excitatory amino acids from intra- to extracellular compartments. J. Cerebr. Blood Flow Metab. 5: 413-419.

Hansen, A. J., J. Hounsgaard, and H. Jahnsen (1982) Anoxia increases potassium conductance in hippocampal nerve cells. Acta Physiol. Scand. 115: 301-310.

Herron, C. E., R. A. J. Lester, E. J. Coan, and G. L. Collingridge (1985) Intracellular demonstration of an $N$-methyl-D-aspartate receptor mediated component of synaptic transmission in the rat hippocampus. Neurosci. Lett. 60: 19-23.

Herron, C. E., R. A. J. Lester, E. J. Coan, and G. L. Collingridge (1986) Frequency-dependent involvement of NMDA receptors in the hippocampus: A novel synaptic mechanism. Nature 322: 265-268.

Honoré, T., J. Lauridsen, and P. Krogsgaard-Larsen (1982) The binding of [ $\left.{ }^{3} \mathrm{H}\right]$ AMPA, a structural analogue of glutamic acid, to rat brain membranes. J. Neurochem. 38: 173-178.

Johansen, F. F., M. B. Jørgensen, D. K. J. Ekström von Lubitz, and N. H. Diemer (1984) Selective dendrite damage in hippocampal CA1 stratum radiatum with unchanged ultrastructure and glutamate uptake after transient cerebral ischemia in the rat. Brain Res. 291: 373377.

Johansen, F. F., M. B. Jørgensen, and N.-H. Diemer (1987) Ischemiainduced delayed ncuronal death in the CA-1 hippocampus is dependent on intact glutamatergic innervation. In Excitatory Amino Acid Transmission, T. P. Hicks, D. Lodge, and H. McLennan, eds., pp. 245-248, Liss, New York.

Jørgensen, M. B., F. F. Johansen, and N.-H. Diemer (1987) Removal 
of the entorhinal cortex protects hippocampal CA-1 neurons from ischemic damage. Acta Neuropathol. (Berl.) 73: 189-194.

Kaplan, T. M., T. M. Lasner, J. V. Nadler, and B. J. Crain (1989) Lesions of excitatory pathways reduce hippocampal cell death after transient forebrain ischemia in the gerbil. Acta Neuropathol. (Berl.) $78: 283-290$.

Kirino, T. (1982) Delayed neuronal death in the gerbil hippocampus following ischemia. Brain Res. 239: 57-69.

Kirino, T., and K. Sano (1984a) Selective vulnerability in the gerbil hippocampus following transient ischemia. Acta Neuropathol. (Berl.) 61: 201-208.

Kirino, T., and K. Sano (1984b) Fine structural nature of delayed neuronal death following ischemia in the gerbil hippocampus. Acta Neuropathol. (Berl.) 62: 209-218.

Kirino, T., A. Tamura, and K. Sano (1984) Delayed neuronal death in the rat hippocampus following transient ischemia. Acta Neuropathol. (Berl.) 64: 139-147.

Krnjević, K., and J. Leblond (1987) Mechanism of hyperpolarizing response of hippocampal cells to anoxia in isolated slices of rat hippocampus. J. Physiol. (Lond.) 382: 79P.

Lee, K., W. Tetzlaff, and G. Kreutzberg (1986) Rapid down regulation of hippocampal adenosine receptors following brief anoxia. Brain Res. 380: 155-158.

Mayer, M. L., and G. L. Westbrook (1987) The physiology of excitatory amino acids in the vertebrate central nervous system. Prog. Neurobiol. 28: 197-276.

Mayer, M. L., A. B. MacDermott, G. L. Westbrook, S. J. Smith, and J. L. Barker (1987) Agonist- and voltage-gated calcium entry in cultured mouse spinal cord neurons under voltage clamp measured using arsenazo III. J. Neurosci. 7: 3230-3244.

McLean, R. A., and B. L. Wclch (1971) A common error in assessing the significance of percentage change in neuropharmacology. J. Pharm. Pharmacol. 23: 643-645.

Meldrum, B. (1985) Excitatory amino acids and anoxic/ischemic brain damage. Trends. Neurosci. 8: 47-48.

Murphy, S. N., S. A. Thayer, and R. J. Miller (1987) The effect of excitatory amino acids on intracellular calcium in single mouse striatal neurons in vitro. J. Neurosci. 7: 4145-4158.

Nadler, J. V., and D. A. Evenson (1989) Use of excitatory amino acids to make axon-sparing lesions of hypothalamus. In Neuroendocrine Peptide Methodology, P. M. Conn, ed., pp. 881-890, Academic, San Diego, CA.

Nadler, J. V., K. W. Vaca, W. F. White, G. S. Lynch, and C. W. Cotman (1976) Aspartate and glutamate as possible transmitters of excitatory hippocampal afferents. Nature 260: 538-540.

Nadler, J. V., B. W. Perry, C. Gentry, and C. W. Cotman (1980) Loss and reacquisition of hippocampal synapses after selective destruction of CA3-CA4 afferents with kainic acid. Brain Res. 191: 387-403.

Nadler, J. V., D. A. Evenson, and G. J. Cuthbertson (1981) Comparative toxicity of kainic acid and other acidic amino acids toward rat hippocampal neurons. Neuroscience 6: 2505-2517.
Olney, J. W. (1983) Excitotoxins: An overview. In Excitotoxins, K. Fuxe, P. Roberts, and R. Schwarcz, eds., pp. 82-96, Macmillan Press, London.

Olverman, H. J., A. W. Jones, and J. C. Watkins (1984) L-Glutamate has higher affinity than other amino acids for [3H]-D-AP5 binding sites in rat brain membranes. Nature 307: 460-462.

Onodera, H., G. Sato, and K. Kogure (1986) Lesions to Schaffer collaterals prevent ischemic death of pyramidal cells. Neurosci. Lett. 68 : 169-174.

Petito, C. K., and W. A. Pulsinelli (1984) Delayed neuronal recovery and neuronal death in rat hippocampus following severe cerebral ischemia: Possible relationship to abnormalities in neuronal processes. J. Cerebr. Blood Flow Metab. 4: 194-205.

Petito, C. K., E. Feldman, W. A. Pulsinelli, and F. Plum (1987) Delayed hippocampal damage in humans following cardiorespiratory arrest. Neurology 37: 1281-1286.

Pulsinclli, W. A., J. B. Brierley, and F. Plum (1982) Temporal profile of neuronal damage in a model of transient forebrain ischemia. Ann. Neurol. 11: 491-498.

Rothman, S. M., and J. W. Olney (1986) Glutamate and the pathophysiology of hypoxic-ischemic brain damage. Ann. Neurol. 19: 105111

Spuler, A., W. Endres, and P. Grafe (1988) Glucose depletion hyperpolarizes guinea pig hippocampal neurons by an increase in potassium conductance. Exp. Neurol. 100: 248-252.

Swanson, L. W., J. M. Wyss, and W. M. Cowan (1978) An autoradiographic study of the organization of intrahippocampal association pathways in the rat. J. Comp. Neurol. 172: 49-84.

Urban, L., K. Neill, B. J. Crain, J. V. Nadler, and G. G. Somjen (1988) Synaptic physiology of hippocampal area CA1 after transient forebrain ischemia in the gerbil. Soc. Neurosci. Abstr. 14: 185.

Vicedomini, J. P., and J. V. Nadler (1987) A model of status epilepticus based on electrical stimulation of hippocampal afferent pathways. Exp. Neurol. 96: 681-691.

Warner, M. A., J. V. Nadler, and B. J. Crain (1990) Effects of NMDA receptor antagonists and body temperature in the gerbil carotid occlusion model of transient forebrain ischemia. In Current and Future Trends in Anticonvulsant, Anxiety, and Stroke Therapy, M. Williams, ed., Liss, New York (in press)

Wieloch, T., O. Lindvall, P. Blomqvist, and F. H. Gage (1985) Evidence for amelioration of ischemic neuronal damage in the hippocampal formation by lesions of the perforant path. Neurol. Res. 7 : 24-26.

Wigström, H., B. Gustafsson, and Y.-Y. Huang (1985) A synaptic potential following single volleys in the hippocampal CA1 region possibly involved in the induction of long-lasting potentiation. Acta Physiol. Scand. 124: 475-478. 